\title{
Effects of protonation and deprotonation on the reactivity of quinolone: A theoretical study
}

\author{
SHABAAN A K Elroby ${ }^{1,2 *}$, HASSAN A Ewais ${ }^{1} \&$ SAADULLAH G Aziz $^{1}$ \\ ${ }^{1}$ Chemistry Department, Faculty of Science, King Abdulaziz University, Jeddah, Saudi Arabia; \\ ${ }^{2}$ Chemistry Department, Faculty of Science, Beni-Suief University, Beni-Suief, Egypt
}

Received April 22, 2011; accepted June 22, 2011; published online February 21, 2012

\begin{abstract}
Quinolones are the subject of much research as antibacterial compounds and as a new class of antitumor agents. The protonation (P) and deprotonation (D) sites and conformations of quinolone were investigated. The proton affinity (PA) on each of the possible sites in 4-oxo-1,4-dihydroquinoline has been calculated by the restricted Hartree-Fock (HF) and density functional theory (DFT) methods with the basis set 6-311G**. The O-site of protonation was found to be strongly favored over the N-site for the studied compound in the gas phase. Deprotonation takes place in quinolone by detachment of the N-H and COOH protons. The PA of the simple quinolone molecule was used to characterize quinolone reactivity with DNA binding sites. The relative stabilities of the syn and anti conformations were investigated at the B3LYP/6-311G** level of theory; the syn form was shown to be slightly more stable. Its conformation seems to be intrastabilized by hydrogen-bonds consisting of a hydroxyl proton with the O10 atom as the acceptor. We computed and discussed the charge-density distribution and electrostatic potential to explain the reactivity of quinolone.
\end{abstract}

protonation, deprotonation, Density functional theory, quinolone, intramolecular hydrogen-bonds

Citation: Shabaan A K E, Hassan A E, Saadullah G A. Effects of protonation and deprotonation on the reactivity of quinolone: A theoretical study. Chin Sci Bull, 2012, 57: 1665-1671, 10.1007/s11434-011-4922-0

Quinolones are well known antibacterial agents, they act by inhibition of DNA replication in bacteria [1]. In the past 16 years, quinolone derivatives have been the subject of much research as a new class of antitumor agents [2-7]. The reaction mechanism of quinolone antibacterial activity has been reported [8] to be via intermolecular hydrogen-bonding with the guanine of bacterial DNA in a gyrase-DNA complex (Scheme 1(a)). The carboxylic and hydroxyl groups are capable of intramolecular hydrogen-bond formation (Scheme 1(b)), which decreases the concentration of quinolone capable of specific interaction with DNA.

Another factor affecting the behavior of the carboxylic groups is the presence of additional proton acceptors in the quinolone molecule. One of the most important chemical processes is the protonation reaction. It not only plays an important role in general chemistry but is also of high

*Corresponding author (email: skamel@kau.edu.sa)<smiles></smiles>

(a)<smiles>Cc1ccccc1NC=C1CO[CH]OC1=O</smiles>

(b)
Scheme 1

physiological relevance. Proton affinities (PA's) are important in mechanistic studies of proton-transfer reactions and in reactions involving protonated and deprotonated organic molecules [9-12]. Therefore, reliable computational predictions of proton affinities are very important. The present work was devoted to investigating quinolone-protonation sites and the relation between acid-base properties 
and intermolecular hydrogen-bonding. The acid-base properties of the compounds were examined and theoretical proton affinities and deprotonation enthalpies were computed. Quinolone compounds have some structural features that should be analyzed. The first of these properties is the possible syn and anti forms of the carboxylic group conformation. Thus, the conformational preferences of quinolones and the effects of intramolecular hydrogen-bonding on the stability of these structures should be investigated. The main scope of this work is to discuss the optimized geometries and the intramolecular hydrogen-bonds of quinolones as a function of the intrinsic basicities and acidities of the sites involved in the hydrogen-bonding interactions.

\section{Computational methods}

All calculations were performed using computational methods incorporated in the Gaussian03W program suite [13]. The molecular structures of the studied species were optimized using density functional theory (DFT) with the B3LYP hybrid exchange-correlation functional and the 6-311G** basis set [14-20]. The geometry optimization results suggested that there was a tendency to form interand intra-molecular hydrogen-bonds. The basis set we use here contains polarization functions on hydrogen; this is particularly useful in dealing with systems where hydrogen could act as a bridging atom. The frequency calculations for all species were performed at the B3LYP/6-311G** level to verify that the geometries were minima on the potential energy surface and to obtain zero-point and thermal corrections $(298.15 \mathrm{~K}, 1 \mathrm{~atm})$ for the determination of the proton affinities. For comparison purposes, some geometry optimizations and frequency calculations were performed at the HF/6-311G** level. The thermodynamic proton affinity of a compound $\mathrm{A}$ is defined as the negative of the enthalpy change, $-\Delta_{\mathrm{r}} H$, for the following gas-phase reaction at standard conditions (usually at $298 \mathrm{~K}$ under a pressure of $\left.1.013 \times 10^{5} \mathrm{~Pa}\right)$.

$$
\mathrm{A}+\mathrm{H}^{+} \rightarrow \mathrm{AH}^{+}
$$

Theoretically, the proton affinities at $0 \mathrm{~K}$ are obtained from the calculated electronic energies, $E_{0}{ }^{\mathrm{el}}$, and the zero-point vibrational energies, $E_{0}{ }^{\text {vib }}$.

\section{Results and discussion}

The determination of PA requires the preliminary investigation of the conformational flexibility of the neutral form of the studied compound and, in particular, the search for the most stable structure. Quinolone may display rotational isomerism. Three typical rotamers, syn 1 , syn 2 , and anti are depicted in Figure 1. The hydroxyl group is in the same direction as the $\mathrm{C} 4-\mathrm{O} 10$ bond in the syn conformer $\mathrm{O} 12$ (for the numbering system, see Figure 1). This group is rotated through $180^{\circ}$ around the C9-O12 bond, and $180^{\circ}$ around the C3-C9 bond in the syn 2 and anti rotamers, respectively. The interesting conformational properties presented by quinolone motivated the present investigation. Several forces may be of importance for the conformational properties of the title compound. The lone-pair electrons of the $\mathrm{O} 10$ atom should have the right symmetry in the syn rotamer to be delocalized into the $\pi$-electron system of the ring. This should lead to stabilization of the syn 1 conformer. Repulsion between the lone-pair electrons of O10, O11, and $\mathrm{O} 12$ is assumed to be another important effect. The minimum repulsive interaction between these lone-pairs and those of O10 should exist in syn 1 .

Table 1 presents the total energies and relative energies for the three stable conformers of quinolone for the HF and B3LYP methods using the 6-311G** basis set.

The electronic energy differences $(\Delta E \mathrm{e})$ between $s y n 1$ and anti, and syn 2 and anti, are found to be 8.018 and 9.778 $\mathrm{kcal} / \mathrm{mol}$, respectively, at the B3LYP/6-31G** level. At the $\mathrm{HF} / 6-311 \mathrm{G}^{* *}$ level, the electronic energy differences are 5.531 and $7.697 \mathrm{kcal} / \mathrm{mol}$ between syn 1 and the syn 2 and anti forms, respectively.

In general, the corresponding $\Delta E$ values obtained through $\mathrm{HF} / 6-311 \mathrm{G} * *$ level are slightly lower $(68 \%-78 \%)$. This electron-correlation effect may be understood from the fact that the electron-correlation energy (approximated as $E_{\text {Corr,I }}$ $=E_{\mathrm{i}}-E_{\mathrm{HF}}$, where $\left.\mathrm{i}=\mathrm{B} 3 \mathrm{LYP}\right)$ stabilizes fully optimized structures, but favors the syn 1 structure. This interaction would stabilize syn 1 relative to syn 2 and anti.

These findings indicate that the absolute minimum is that
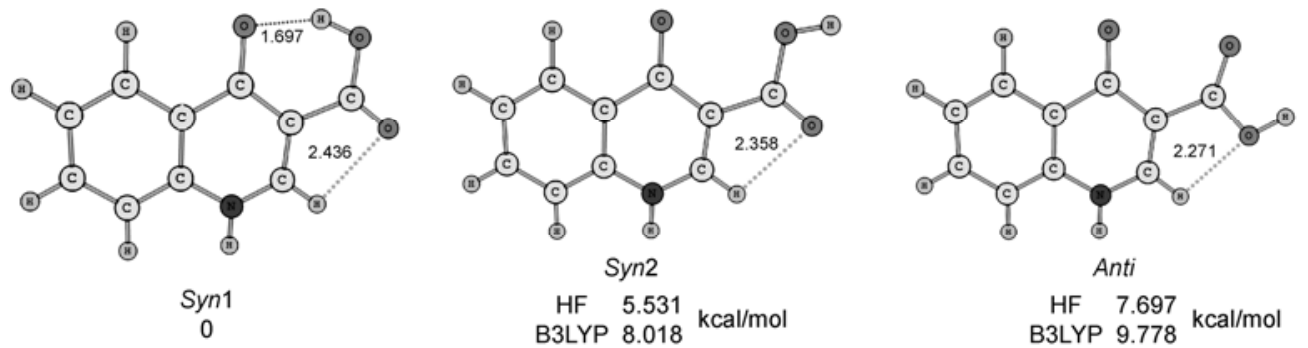

Figure 1 B3LYP/6-311G** optimized structures of the most stable conformers of quinolone. 
Table 1 Calculated energies (a.u.) and relative energies ( $\mathrm{kcal} / \mathrm{mol}$ ) of the three stable conformers of quinolone at the HF/6-311G** and B3LYP/ 6-311G** levels

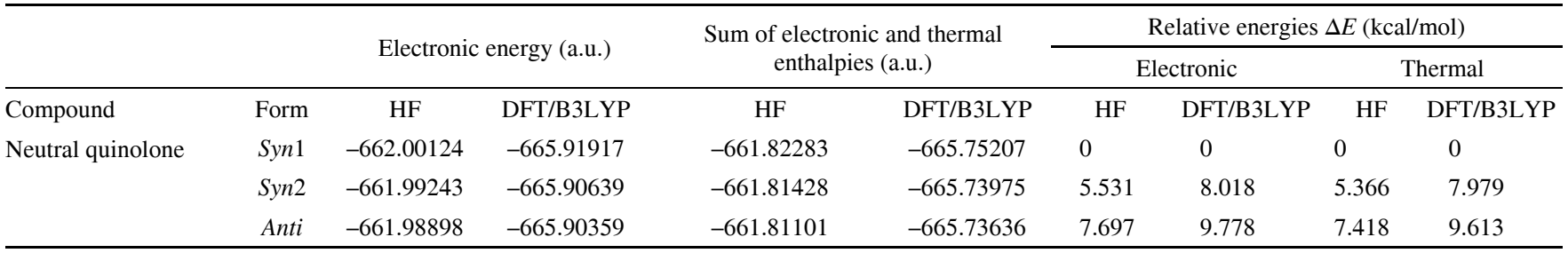

in which the hydrogen atom of the hydroxyl group in the carboxylic group donates a hydrogen-bond to the oxygen in position 4 in the syn 1 form (Figure 1). The second-closest conformation to syn 1 form can be defined as syn2. In this conformation, the internal hydrogen-bonding interaction between the hydrogen atom of the hydroxyl group and the lone-pair of the carbonyl of the carboxylic group occurs (Figure 1).

The internal hydrogen-bonds between the hydrogen atoms and lone-pairs of oxygen atoms (Figure 1) play an important role in the stability of syn conformers.

An energy difference of about $2 \mathrm{kcal} / \mathrm{mol}$ has been determined for the syn 2 and anti conformers. A delicate balance between stabilizing intramolecular hydrogen-bonds and destabilizing steric and repulsive lone-pair electrons results in different low-energy conformations.

Table 2 shows a comparison of geometrical parameters calculated at the B3LYP/6-311G** level and the crystal data available in the literature.

Close inspection of the data presented in this table reveals that the rotation of the carboxylic group has caused some marked geometrical variations; these may be summarized as follows:

(1) The C4-O10 bond length gets shorter. This indicates that the $\pi$-system has increased at the carbonyl group in the 4-position. This would lead to much tighter binding in this region. The $\mathrm{C} 4-\mathrm{O} 10$ bond length is about $1.243 \AA$ for syn 1 , longer than for the other structures (syn 2 and anti). This is evidence for the intramolecular hydrogen-bond between $\mathrm{O} 10$ and $\mathrm{H} 11$ in syn 1.

(2) The bond distances of the two intramolecular hydrogen-bonds in the syn 1 form are $1.696 \AA(\mathrm{O} 10-\mathrm{H} 13)$ and $2.432 \AA(\mathrm{O} 11-\mathrm{H} 8)$. In contrast, the bond distance of the intramolecular hydrogen-bond in the anti form is $2.343 \AA$ (O11-H8).

(3) For the $\operatorname{syn} 1$ form, the bond lengths computed by DFT combined with the $6-311 \mathrm{G}^{* *}$ basis set are in very good agreement with the experimental values. For example, for the syn 1 form, the $\mathrm{C} 4-\mathrm{O} 10$ and $\mathrm{C} 2-\mathrm{C} 3$ distances calculated at this level of theory are in better agreement with the experimental values of 1.255 and $1.365 \AA$ [21] than the bond lengths of 1.210 and $1.352 \AA$ computed at the $\mathrm{HF} / 6-311 \mathrm{G}^{* *}$ level are. The involvement of these groups in hydrogen-bonds and other intramolecular interactions in the crystal would account for these differences.

We also plotted the electrostatic potential (isopotential surface) to determine in which regions surrounding quinolone a particular negative electrostatic potential will be felt. The electrostatic potential (the energy of interaction of a positive point charge with the nucleus and electrons of a molecule) mapped onto an electron density isosurface may be employed to distinguish regions on the surface which are electron-rich (subject to nucleophilic attack) from those which are electron-poor (subject to electrophilic attack) [22]. We obtained and examined an electrostatic potential map (Figure 2) for quinolone using a 6-311G** Hartree-Fock

Table 2 Experimental and calculated structural parameters of the studied compound (distances in $(\AA)$, angles in $\left(^{\circ}\right)$ ) at the HF/6-311G** and B3LYP/ 6-311G** levels

\begin{tabular}{|c|c|c|c|c|c|c|c|}
\hline \multirow{2}{*}{ Parameter } & \multirow{2}{*}{$\frac{\text { Experimental }}{\text { X-ray }}$} & \multicolumn{2}{|c|}{ Syn 1} & \multicolumn{2}{|c|}{ Syn2 } & \multicolumn{2}{|c|}{ Anti } \\
\hline & & $\mathrm{HF}$ & DFT B3LYP & $\mathrm{HF}$ & DFT B3LYP & $\mathrm{HF}$ & DFT B3LYP \\
\hline C6-C5 & 1.407 & 1.390 & 1.408 & 1.388 & 1.405 & 1.387 & 1.404 \\
\hline C6-N1 & 1.374 & 1.383 & 1.388 & 1.386 & 1.391 & 1.386 & 1.391 \\
\hline $\mathrm{C} 4-\mathrm{C} 5$ & 1.440 & 1.477 & 1.475 & 1.493 & 1.496 & 1.492 & 1.495 \\
\hline C3-C4 & 1.430 & 1.455 & 1.453 & 1.472 & 1.474 & 1.475 & 1.477 \\
\hline C4-O10 & 1.255 & 1.210 & 1.243 & 1.194 & 1.221 & 1.192 & 1.219 \\
\hline $\mathrm{C} 3-\mathrm{C} 9$ & - & 1.495 & 1.502 & 1.482 & 1.484 & 1.479 & 1.479 \\
\hline $\mathrm{N} 1-\mathrm{C} 2$ & 1.341 & 1.339 & 1.350 & 1.339 & 1.349 & 1.341 & 1.352 \\
\hline C9-O11 & 1.198 & 1.186 & 1.209 & 1.193 & 1.216 & 1.178 & 1.202 \\
\hline C9-O12 & 1.329 & 1.312 & 1.333 & 1.315 & 1.343 & 1.345 & 1.375 \\
\hline O10-H13 & 1.640 & 1.815 & 1.697 & - & - & - & - \\
\hline
\end{tabular}




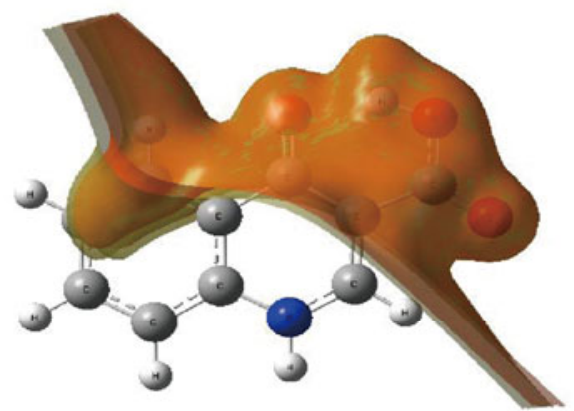

(a)

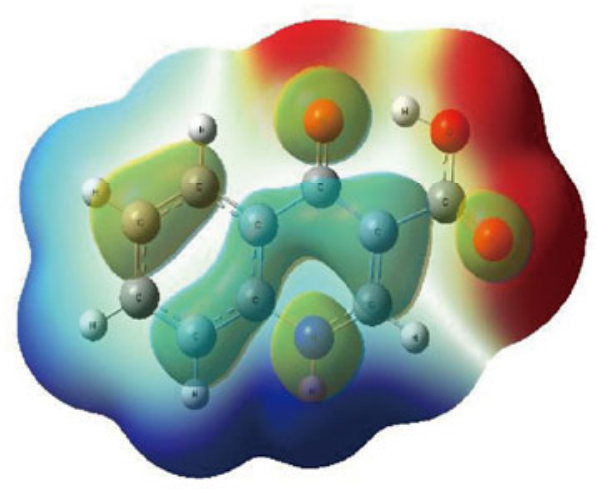

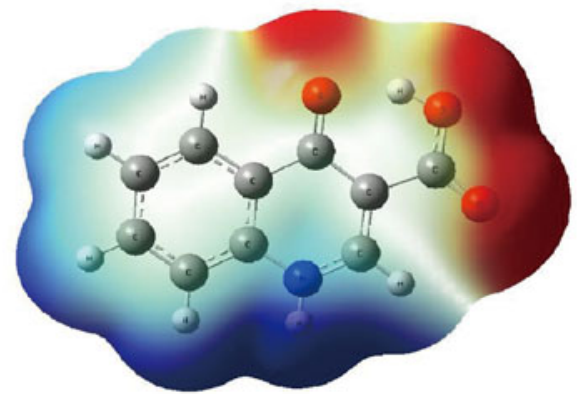

(b)

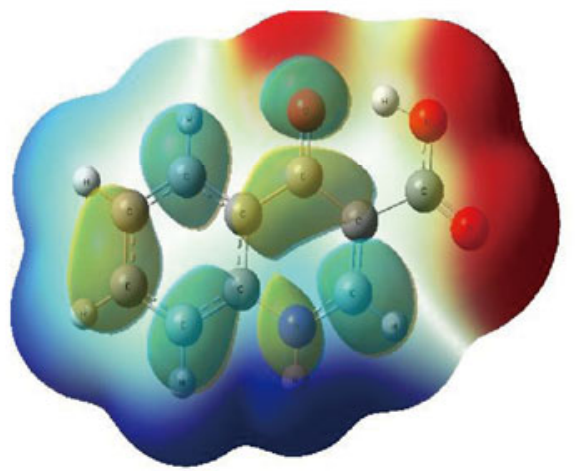

(c)

Figure 2 Isopotential surface (a), electrostatic potential map (b), and HOMO and LUMO graphical model (c) for quinolone at the B3LYP/6-311G** level.

calculation. In Figure 2, red colors represent large negative values of the potential, and blue colors represent large positive values (orange, yellow, and green represent intermediate values of the potential).

Figure 2 shows, as expected, a negative charge (red) near the carboxylic and carbonyl groups and a central region which is neutral (green). This means that the hydrogen-bond has been formed by these atoms (O10 and O12) with DNA-guanine (responsible for the antibacterial properties of quinolone).

The HOMO and LUMO graphical model indicates that the oxygen atom in position 4 is conjugated with the adjacent ring. The HOMO is delocalized on the molecule, except for the hydroxyl group, but the LUMO, excluding the carboxylic group, is localized on two rings of the molecule.

From the graphical model, we concluded that a positive charge is delocalized on the benzene ring. This means that the benzene ring is subject to nucleophilic attack. Furthermore, the negative partial charge is concentrated on the carbonyl and carboxylic groups. Our results are in good agreement with experimental data which indicated that interaction between quinolone and DNA sites occurs via the carbonyl and carboxylic groups (Scheme 1(a)).

Proton affinities. The two oxygen atoms (O10 and O12) in the studied compound act as acceptors, forming hydrogen-bonds with DNA sites. Hence, it is of primary importance to know the proton- cceptor and proton-donor abilities of this compound. The proton affinity (PA) of the quinolone molecule has been used to characterize its reactivity with DNA sites. The PA (B) values of the $\mathrm{O} 10$ and $\mathrm{N} 1$ atoms and the $\mathrm{DP}\left(\mathrm{A}^{-}\right)$values of the $\mathrm{N} 1 \mathrm{H}$, and $\mathrm{COOH}$ of quinolone are listed in Table 3 . The three-dimensional minimum energy geometries of the protonated and unprotonated molecules, calculated at the HF/6-311G** and B3LYP/6-311G** levels, are shown in Figure 3. All calculations converged on stationary points that were true minima, as indicated by the vibrational frequency calculations, which yielded positive frequencies only. Table 4 summarizes the calculated energies of the neutral, deprotonated, and protonated forms of the studied compound using the HF and B3LYP methods. In these calculations, the protonation energies calculated by the DFT method are much higher than those obtained by HF. Let us consider the protonation processes at the $\mathrm{N}$ - and O-protonation sites in more detail. The calculations indicate that the most-stable structures of the protonated forms are those in which a proton is bonded to the oxygen atom $(\mathrm{O} 10)$ at position 4 . These results indicate that $\mathrm{O} 10$ prefers to accept a hydrogen atom from DNA sites. The average difference in the PA enthalpies between $\mathrm{P}(\mathrm{N} 1)$ and $\mathrm{P}(\mathrm{O} 10)$ is about $38.0 \mathrm{kcal} / \mathrm{mol}$, by two calculation methods. Table 4 shows that the acidity of the $\mathrm{N} 1 \mathrm{H}$ bond in the gas phase is significantly larger than that of the $\mathrm{OH}$ in the carboxylic group. As indicated by the very short H13-O10 distances of 1.708 and $1.591 \AA$ obtained by the B3LYP and HF methods, respectively, an intramolecular hydrogen-bond is present in this molecule. The existence of 
Table 3 Calculated structural parameters for neutral, protonated, and deprotonated forms of the studied compound (distances in $(\AA)$, angles in $\left(^{\circ}\right)$ ) at the $\mathrm{HF} / 6-311 \mathrm{G}^{* *}$ and B3LYP/6-311G** levels

\begin{tabular}{|c|c|c|c|c|c|c|c|c|c|c|c|c|}
\hline \multirow{2}{*}{$\begin{array}{l}\text { Compound } \\
\text { parameters }\end{array}$} & \multicolumn{2}{|c|}{ Syn 1} & \multicolumn{2}{|c|}{$\mathrm{P}(\mathrm{N} 1)$} & \multicolumn{2}{|c|}{$\mathrm{P}(\mathrm{O} 4)$} & \multicolumn{2}{|c|}{$\mathrm{P}(\mathrm{NO})$} & \multicolumn{2}{|c|}{$\mathrm{COO}^{-}$} & \multicolumn{2}{|c|}{$\mathrm{N}^{-}$} \\
\hline & B3LYP & $\mathrm{HF}$ & B3LYP & $\mathrm{HF}$ & B3LYP & $\mathrm{HF}$ & B3LYP & $\mathrm{HF}$ & B3LYP & $\mathrm{HF}$ & B3LYP & $\mathrm{HF}$ \\
\hline C6-C5 & 1.408 & 1.390 & 1.382 & 1.395 & 1.398 & 1.420 & 1.418 & 1.406 & 1.392 & 1.409 & 1.401 & 1.424 \\
\hline C6-N1 & 1.388 & 1.383 & 1.479 & 1.494 & 1.373 & 1.380 & 1.488 & 1.473 & 1.367 & 1.375 & 1.365 & 1.372 \\
\hline $\mathrm{C} 4-\mathrm{C} 5$ & 1.475 & 1.477 & 1.483 & 1.480 & 1.430 & 1.431 & 1.430 & 1.429 & 1.507 & 1.511 & 1.466 & 1.464 \\
\hline $\mathrm{C} 3-\mathrm{C} 4$ & 1.453 & 1.455 & 1.495 & 1.492 & 1.389 & 1.400 & 1.456 & 1.461 & 1.473 & 1.469 & 1.421 & 1.429 \\
\hline $\mathrm{C} 4-\mathrm{O} 10$ & 1.243 & 1.210 & 1.187 & 1.218 & 1.312 & 1.335 & 1.298 & 1.269 & 1.197 & 1.226 & 1.240 & 1.270 \\
\hline $\mathrm{C} 2-\mathrm{C} 3$ & 1.366 & 1.352 & 1.314 & 1.329 & 1.385 & 1.390 & 1.339 & 1.323 & 1.341 & 1.358 & 1.405 & 1.407 \\
\hline $\mathrm{C} 3-\mathrm{C} 9$ & 1.502 & 1.495 & 1.535 & 1.541 & 1.517 & 1.526 & 1.575 & 1.560 & 1.565 & 1.582 & 1.475 & 1.484 \\
\hline $\mathrm{N} 1-\mathrm{C} 2$ & 1.350 & 1.339 & 1.464 & 1.476 & 1.313 & 1.331 & 1.467 & 1.455 & 1.370 & 1.375 & 1.299 & 1.321 \\
\hline C9-O11 & 1.209 & 1.186 & 1.174 & 1.198 & 1.176 & 1.199 & 1.191 & 1.167 & 1.235 & 1.257 & 1.196 & 1.219 \\
\hline C9-O12 & 1.333 & 1.312 & 1.300 & 1.320 & 1.307 & 1.330 & 1.315 & 1.295 & 1.214 & 1.237 & 1.324 & 1.345 \\
\hline O10-H13 & 1.697 & 1.815 & 1.910 & - & 1.954 & 1.906 & 2.024 & 2.050 & - & - & 1.708 & 1.591 \\
\hline
\end{tabular}

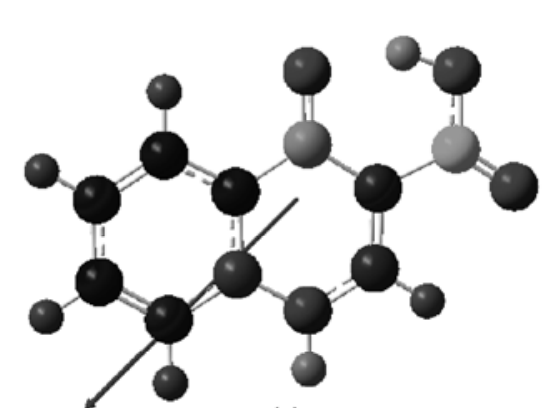

(a)

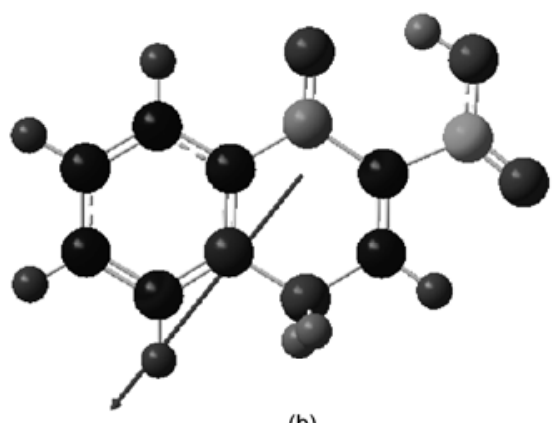

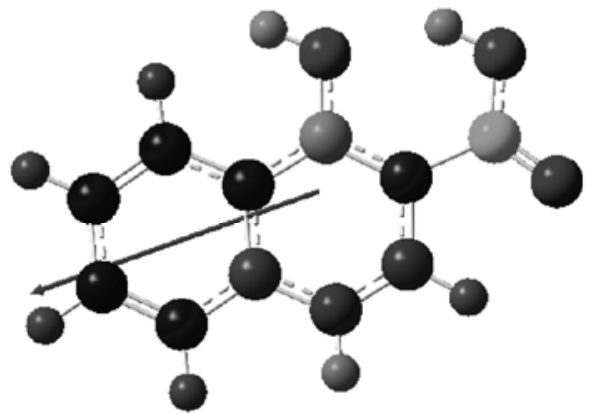

(c)

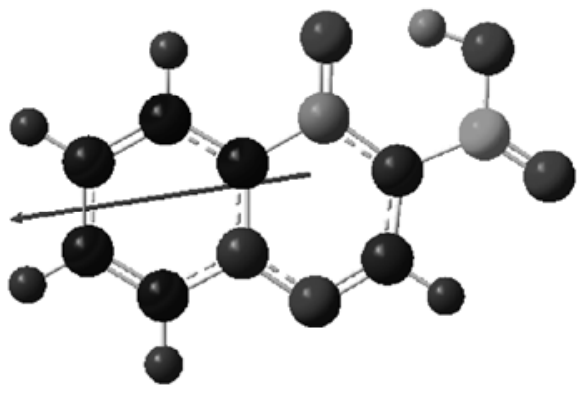

(e)

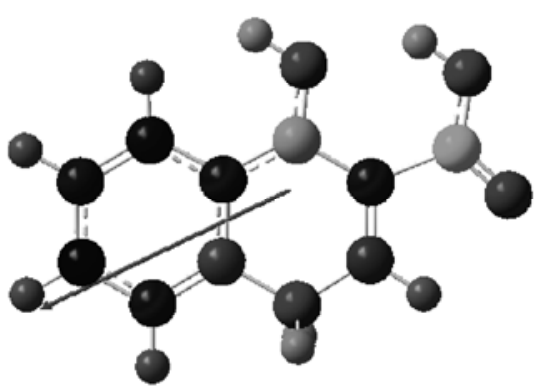

(d)

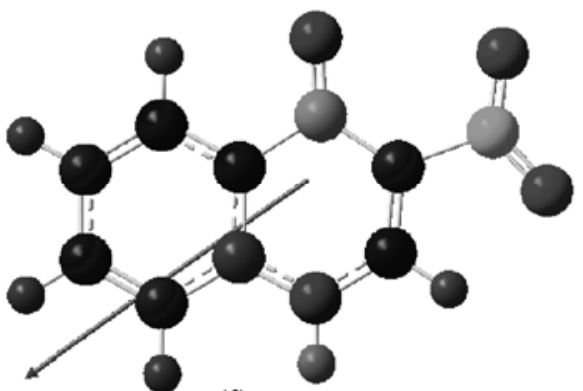

(f)

Figure 3 Geometric configurations, charge distributions, and directions of dipole moment vectors of: (a) neutral, (b) N-protonated [P(N)], (c) O-protonated $[\mathrm{P}(\mathrm{O})]$, (d) diprotonated $[\mathrm{P}(\mathrm{NOH})],(\mathrm{e}) \mathrm{N}$-anion $\left(\mathrm{N}^{-}\right)$, and (f) carboxylate anion $\left(\mathrm{COO}^{-}\right)$. 
Table 4 Calculated total energies (a.u.) and relative energies ( $\mathrm{kcal} / \mathrm{mol}$ ) for the studied protonated and deprotonated forms at the B3LYP/6-311G** and $\mathrm{HF} / 6-311 \mathrm{G}^{* *}$ levels

\begin{tabular}{|c|c|c|c|c|c|c|c|c|}
\hline & \multirow{2}{*}{\multicolumn{2}{|c|}{ Electronic energy (a.u.) }} & \multirow{2}{*}{\multicolumn{2}{|c|}{$\begin{array}{c}\text { Sum of electronic and thermal } \\
\text { enthalpies (a.u.) }\end{array}$}} & \multicolumn{4}{|c|}{ Relative energies $(\Delta E)(\mathrm{kcal} / \mathrm{mol})$} \\
\hline & & & & & \multicolumn{2}{|c|}{ Electronic } & \multicolumn{2}{|c|}{ Thermal } \\
\hline & $\mathrm{HF}$ & DFT & $\mathrm{HF}$ & DFT & $\mathrm{HF}$ & DFT & $\mathrm{HF}$ & DFT \\
\hline N-protonated & -662.29476 & -666.20587 & -662.10217 & -666.02595 & 184.182 & 179.901 & 175.281 & 171.859 \\
\hline O-protonated & -662.35536 & -666.26761 & -662.16358 & -666.08774 & 222.210 & 218.645 & 213.820 & 210.632 \\
\hline NO-protonated & -662.47192 & -666.38171 & -662.26752 & -666.19044 & 295.348 & 290.239 & 279.043 & 275.077 \\
\hline $\mathrm{N}$-anion & -661.46644 & -665.39196 & -661.30272 & -665.23913 & -335.585 & -330.827 & -326.368 & -321.874 \\
\hline COO-anion & -661.40984 & -665.33552 & -661.24797 & -665.18310 & -371.106 & -366.240 & -360.728 & -357.031 \\
\hline
\end{tabular}

this bond is also indicated by natural bond orbital analysis (NBO), which shows a significant amount of electron transfer from the $\mathrm{O} 10$ lone-pair orbital to the antibonding orbital of O11-H13.

As a further interesting feature, we note that the deprotonation of the $\mathrm{NH}$ group increases the negative charges on $\mathrm{O} 10$ and by up to $15 \%$. In contrast, the protonation of $\mathrm{NH}$ decreases the negative charges on these oxygen atoms by about $21 \%$. This means that the efficiency of this compound in binding with DNA sites to form strong hydrogen-bonds increases in basic media. Tables 2 and 3 report some relevant geometrical parameters, distances, and NBO charge distributions for the most stable conformer and the five ionic forms of quinolone (protonated and deprotonated forms). In all cases studied, the bond lengths for the six-membered ring appear to be almost unaffected. Our results show that the $\mathrm{O} 10-\mathrm{H} 13$ bond involved in the interaction is elongated to values ranging from $0.018\left(\mathrm{~N}^{-}\right)$to $0.332 \AA[\mathrm{P}(\mathrm{NO})]$; the largest elongation corresponds to the smallest $\mathrm{C} 4-\mathrm{O} 11$ intramolecular distance of $1.697 \AA$. A summary of the structural parameters is given in Tables 2 and 3 . We suggest that intramolecular hydrogen-bonding is contributing to the overall stability of the $\mathrm{P}(\mathrm{O} 4)$ and $\mathrm{N}^{-}$forms. From this detailed study of the electronic structure and protonation of the studied quinolone, it may be concluded that the O-site of protonation in the gas phase is preferred over the NH sites. The intramolecular hydrogen-bond greatly affects the stability of the protonated and deprotonated forms. Natural bond orbital (NBO) [23] charge calculations at the B3LYP/ $6-311 \mathrm{G}^{* *}$ level were performed to examine the stability and the reactivity of the protonated and deprotonated forms of quinolone. Figure 3 shows the charge disruptions and the directions of the dipole moment vectors for the parent compound and its protonated and deprotonated forms. As shown in Figure 3, in the parent compound, the dipole moment vector is directed from the heterocyclic ring to the benzene ring. This means that the negative charge on the benzene ring decreases.

\section{Conclusion}

In this study, fundamental information on the electronic and acid-base properties of quinolone, which is commonly used as an antibacterial agent and acts by inhibition of DNA replication in bacteria, was reported. The results obtained in the present work allow us to establish a possible explanation of the correlation between the acid-base properties of quinolone and its hydrogen-bond-forming reactivity. From our investigations, it is possible to draw the following conclusions.

(1) In the solid phase, quinolone was shown by X-ray diffraction experiments to exist in a syn orientation. In the present work, the relative stabilities of both the syn and anti conformations were investigated at the B3LYP/6-311G** and $\mathrm{HF} / 6-311 \mathrm{G}^{* *}$ levels; the syn 1 form was shown to be slightly more stable than the syn 2 and anti forms, by 8.018 and $9.778 \mathrm{kcal} / \mathrm{mol}$, respectively. The results indicate that the stability of the syn form over the other forms is the result of decreased dipole-dipole repulsion and formation of intramolecular hydrogen-bonds.

(2) The computed geometrical parameters at the B3LYP/6-311G** level are in good agreement with those determined experimentally by X-ray diffraction.

(3) The studied compound exhibits two protonation sites, both in the heterocyclic ring, via the $\mathrm{NH}$ and the $\mathrm{O}$ atom. Protonation introduces pronounced geometry deformations and charge distributions. The most drastic deformation is that associated with protonation of the $\mathrm{O}$-atom. On the other hand, quinolone has two deprotonation sites $(\mathrm{NH}$ and $\mathrm{COOH})$. Our results indicate that deprotonation of $\mathrm{NH}$ greatly affects the charge distributions on a very important moiety in the studied compound.

This work was supported by the Deanship of Scientific Research (DSR) King Abdulaziz University, Jeddah (19/130/1431).

1 Dax S L. Antibacterial Chemotherapeutic Agents. Glasgow: Blackie, 1997. 298

2 Kuo S C, Lee H Z, Juang J P, et al. Synthesis and cytotoxicity of 1,6,7,8-substituted 2-(4'-substituted phenyl)-4-quinolones and related compounds: Identification as antimitotic agents interacting with tubulin. J Med Chem,1993, 36: 1146-1156

3 Lai Y Y, Huang L J, Lee K H, et al. Synthesis and biological relationships of 3',6-substituted 2-phenyl-4-quinolone-3-carboxylic acid derivatives as antimitotic agents. Bioorg Med Chem, 2005, 13: 265-275 
4 Larsen A K, Escargueil A E, Skladanowski A. Catalytic topoisomerase II inhibitors in cancer therapy. Pharmacol Ther, 2003, 99: 167-181

5 Li L,Wang H K, Kuo S C, et al. 2',3',4',5',5,6,7-Substituted 2-phenyl4-quinolones and related compounds: Their synthesis, cytotoxicity, and inhibition of tubulin polymerization. J Med Chem, 1994, 37: 1126-1135

6 Li L, Wang H K, Kuo S C, et al. Antitumor agents 155. Synthesis and biological evaluation of 3',6,7-substituted 2-phenyl-4-quinolones as antimicrotubule agents. J Med Chem, 1994, 37: 3400-3407

7 Yoshinori Y, Tadashi A, Makoto M, et al. Antitumor quinolones with mammalian topoisomerase II mediated DNA cleavage activity. Cancer Res, 1992, 52: 2818-2822

8 Shen L L, Mitscher L A, Sharma P N, et al. Mechanism of inhibition of DNA gyrase by quinolone antibacterials: A cooperative drugDNA binding model. Biochemistry, 1989, 28: 3886-3894

9 DeFrees D J, Mclean A D. Ab initio determination of the proton affinities of small neutral and anionic molecules. J Comput Chem, 1986, 7: 321-333

10 Beelen E S E, Koblenz T A, Ingemann S, et al. Experimental and theoretical evaluation of proton affinities of furan, the mthylphenols, and the related anisoles. J Phys Chem, 2004, 108: 2787-2793

11 Scheiner S, Wang L. Hydrogen bonding and proton transfers of the amide group. J Am Chem Soc, 1993, 115: 1958-1963

$12 \mathrm{Ai} \mathrm{H}, \mathrm{Bu} \mathrm{Y}, \mathrm{Li} \mathrm{P}$, et al. Marked Iincrements of stability and proton affinity of the protonated, zwitterionic glycine induced by the attachment of two excess electrons. J Phys Chem, 2004, 108: 41564162

13 Frisch M J. Gaussian 03, Revision A, 11.3. Pittsburgh PA: Gaussian
Inc, 2003

14 Becke A D. Density-functional exchange-energy approximation with correct asymptotic behavior. Phys Rev A, 1988, 38: 3098-3100

15 Lee C, Yang W, Parr R G. Development of the Colle-Salvetti correlation-energy formula into a functional of the electron density. Phys Rev B, 1988, 37: 785-789

16 Becke A D. Density-functional thermochemistry. III. The role of exact exchange. J Chem Phys, 1993, 98: 5648-5652

17 Sim F, St-Amant A, Papai I, et al. Gaussian density functional calculations on hydrogen-bonded systems. J Am Chem Soc, 1992, 114: 4391-4400

18 Latajka Z, Bouteiller Y. Structures of the water hexamer using density functional methods. J Chem Phys, 1994, 101: 4472-4474

19 Kim K, Jordan K D. Comparison of density functional and MP2 calculations on the water monomer and dimer. J Phys Chem, 1994, 98: 10089-10094

20 Chandra A K, Nguyen M T, Zeegers-Huyskens T. Theoretical study of the interaction between thymine and water. Protonation and deprotonation enthalpies and comparison with Uracil. J Phys Chem A, 1998, 102: 6010-6016

21 Głowka M L. Intramolecular hydrogen bond between 4-oxo and 3carboxylic groups in quinolones and their analogs. Crystal structures of 7-methyl- and 6-fluoro-1,4-dihydro-4-oxocinnoline-3-carboxylic acids. J Mol Struct, 2003, 658: 43-50

22 Hehre W J. A Guide to Molecular Mechanics and Quantum Chemical Calculations. Irvine CA: Wavefunction Inc, 2003. Chapter 4 and 19

23 Nelson J T, Pietro W J. Natural bond orbital (NBO) analysis of substituent effects in borazine derivatives. Inorg Chem, 1986, 28: 544-548

Open Access This article is distributed under the terms of the Creative Commons Attribution License which permits any use, distribution, and reproduction in any medium, provided the original author(s) and source are credited. 